\title{
LA EXISTENCIA DE NOCIONES DIVERSAS DE DISCRIMINACIÓN EN EL DERECHO A NO SER DISCRIMINADO EN CHILE. UN ANÁLISIS A TRAVÉS DE DOS ACCIONES DE JUSTICIA CONSTITUCIONAL'
}

The existence of diverse notions of discrimination
in the right not to be discriminated in Chile. An
analysis through two constitutional justice actions

\author{
ESTEFANÍA ESPARZA-REYES ${ }^{2}$ \\ Universidad de La Frontera \\ estefania.esparza@ufrontera.cl
}

SOLEDAD MORALES-TRAPP 3

Universidad de La Frontera

soledad.morales@ufrontera.cl

Cómo citar/Citation

Esparza-Reyes, E. y Morales-Trapp, S. (2021).

La existencia de nociones diversas de discriminación en el derecho a no ser discriminado en Chile. Un análisis a través de dos acciones de justicia constitucional. Anuario Iberoamericano de Justicia Constitucional, 25(2), 431-456. doi: https://doi.org/10.18042/cepc/aiic.25.13

Resumen

Este trabajo tiene por finalidad analizar críticamente la existencia de nociones diversas de discriminación en el derecho a no ser discriminado/a en Chile,

1 Trabajo financiado parcialmente por la Universidad de La Frontera, proyecto DI20-0057.

2 Doctora en Derecho Constitucional por la UCLM. Académica del Departamento de Ciencias Jurídicas de la Universidad de La Frontera, Temuco, Chile. Miembro del Centro de Investigación sobre Desafíos Internacionales (CIDI). Este trabajo es resultado parcial del proyecto Fondecyt-INI 11170788 «Configuración de las bases del Derecho Antidiscriminatorio en Chile a través de sus principios jurídicos».

3 Magíster en Ciencias Sociales Aplicadas por la Universidad de La Frontera. Estudiante de Doctorado en Estado de Derecho y Gobernanza Global de la Universidad de Salamanca. Académica Escuela de Derecho, Universidad de La Frontera, Temuco, Chile. Agradecimientos al proyecto IF20-0011 de la Universidad de La Frontera. 
ejemplificando a través de dos acciones de justicia constitucional. Para ello describirá la conceptualización del derecho a no ser discriminado/a en Chile, especialmente desde la perspectiva de la ausencia/presencia del elemento grupal de la discriminación, contrastándolo con las nociones que priman actualmente en otros sistemas jurídicos, como el español. Continuará exponiendo, brevemente, los principales mecanismos directos de protección del derecho a no ser discriminado/a en Chile, haciendo especial referencia a los mecanismos jurisdiccionales de protección más extendidos y que protegen expresamente el derecho consagrado en el artículo $19 \mathrm{~N}^{\circ} 2$ de la Constitución: la acción de no discriminación arbitraria y la acción de protección. Concluirá con algunas reflexiones críticas sobre las consecuencias de la adopción de nociones diversas de discriminación por parte de los tribunales de justicia encargados de velar por el derecho a no ser discriminado/a.

\section{Palabras clave} mentales.

No discriminación; igualdad; acciones judiciales; protección; derechos funda-

\section{Abstract}

The purpose of this paper is to analyze critically the existence of different notions of discrimination in the right not to be discriminated against in Chile, based on two actions of constitutional justice. For this, it will describe the conceptualization of the right not to be discriminated against in Chile, especially from the absence / presence of the group element of the discrimination, contrasting it with the notions that currently prevail in other legal systems, such as Spanish system. It will continue briefly explaining the main direct mechanisms of protection of the right not to be discriminated against in Chile, making special reference to the most extended jurisdictional mechanisms of protection: the action of non-arbitrary discrimination and the protection action. It will conclude with some critical reflections about consequences of the adoption of different notions of discrimination by the courts of justice.

\section{Keywords}

Non discrimination; equality; judicial action; protection; human rights. 


\section{SUMARIO}

I. INTRODUCCIÓN. II. IGUALDAD Y NO DISCRIMINACIÓN. BREVES ASPECTOS CONCEPTUALES: 1. La relación entre el derecho a la igualdad y la no discriminación. 2. Las definiciones de la discriminación y sus elementos. 3. Los elementos de la discriminación y la no subordinación. 4. La no discriminación en Chile. La convivencia de distintas nociones de discriminación. III. MECANISMOS DE PROTECCIÓN DE LA NO DISCRIMINACIÓN EN CHILE. BREVE PANORAMA GENERAL. IV. LA ACCIÓN DE PROTECCIÓN Y LA ACCIÓN DE NO DISCRIMINACIÓN ARBITRARIA:

1. Aspectos generales. 2. Aspectos procedimentales relevantes de la acción de no discriminación arbitraria y la acción de protección. V. CONCLUSIONES. BibLOGRAFíA.

\section{INTRODUCCIÓN}

El reconocimiento de un contenido material al derecho a la igualdad, consistente en la prohibición de ser discriminado/a, ha representado un enorme desafío para el constitucionalismo. La superación de una concepción formal que no consideraba circunstancias fácticas de ningún tipo; el marcado carácter social de la aplicación de la no discriminación, que abarca interacciones sociales de todo tipo y en cualquier ámbito; el componente volitivo de la discriminación, que implica una minusvaloración de otros grupos sociales; la naturalización de los prejuicios en los cuales se basa, entre otros muchos factores, ocasionaron que su incorporación a los distintos ordenamientos jurídicos no fuese homogénea en cuanto a la forma de entenderla y a sus mecanismos de protección, circunstancia que se produjo con posterioridad.

El desarrollo y expansión de los sistemas regionales y universal de protección de los derechos humanos colaboró con la adopción de un concepto de discriminación más o menos análogo en las distintas latitudes. Sin embargo, este proceso, por diversos factores, no se produjo en Chile. En dicho país, según se verá, el concepto de discriminación es distinto del contenido que se ha extendido en otros puntos del globo. Particularmente, pareciera ser que ha primado un concepto de discriminación en el cual no se considera para su configuración un elemento grupal o que considere la pertenencia a grupos sociales discriminados/subordinados.

Esta conceptualización diversa de la discriminación genera importantes consecuencias en distintos niveles, donde uno de los más destacables está constituido por las formas de proteger el derecho asociado, específicamente por los 
mecanismos judiciales para resguardar el derecho constitucional a no ser discriminado/a.

El presente trabajo tiene por objetivo analizar críticamente la existencia de nociones diversas de discriminación en la protección del derecho a no ser discriminado/a en Chile a través de dos acciones de justicia constitucional.

Así, desde la dogmática jurídica, se analizará la conceptualización del derecho a no ser discriminado/a en Chile, contrastándolo con las nociones que priman actualmente en otros sistemas jurídicos. Se continuará exponiendo brevemente los principales mecanismos directos de protección del derecho a no ser discriminado/a en Chile, haciendo especial referencia a los mecanismos jurisdiccionales más extendidos que hacen referencia explícita a la protección al derecho a la igualdad establecido en el artículo $19 \mathrm{~N}^{\circ} 2$ de la Constitución: la acción de no discriminación arbitraria y la acción de protección. La elección de estas dos acciones en desmedro de otras se basó en que se trata de acciones no sectoriales y que, por ello, presentan un mayor alcance en los diversos ámbitos. Al finalizar, se abordarán algunas reflexiones críticas, a modo de conclusiones, sobre las particularidades de estas dos vías de protección y la forma en que la conceptualización de la discriminación influye en la configuración y aplicación del derecho a no ser discriminado/a en Chile.

\section{IGUALDAD Y NO DISCRIMINACIÓN. BREVES ASPECTOS CONCEPTUALES}

Para entender la forma en que el sistema jurídico chileno protege el derecho a no ser discriminado/a, resulta esencial referirse al concepto de discriminación. Lo anterior se debe a que su conceptualización es diversa a las nociones más asentadas en los distintos sistemas jurídicos, y a que su protección encuentra en esta diferencia motivos para una regulación original.

\section{LA RELACIÓN ENTRE EL DERECHO A LA IGUALDAD Y LA NO DISCRIMINACIÓN}

Aunque existen antecedentes del derecho a la igualdad en distintas civilizaciones antiguas, Esparta, Roma, Egipto, entre otras (Martín, 2004: 23 y ss.), lo cierto es que su primera consagración jurídica se produjo en las declaraciones de derechos de fines del siglo XVIII. La intención de la consagración de la igualdad en estas declaraciones, particularmente en la Declaración de Derechos del Hombre y del Ciudadano de 1789, fue la abolición de los privilegios, entendidos como circunstancias que contrariaban la igualdad natural del ser humano. Sin embargo, la manera concreta en la cual se plasmó este postulado fue formal, a través de la prohibición de las leyes ad personam y la generalidad y abstracción en la redacción 
de las normas jurídicas, así como la aplicación idéntica de la ley, sin distinción de su destinatario.

Ahora bien, resulta necesario evidenciar la distinción entre finalidad y forma en que se consagró el derecho a la igualdad, puesto que durante muchos años se identificó completamente la igualdad, con su forma de plasmación. Entonces, esta concepción obvió que la finalidad del derecho a la igualdad era la eliminación de los privilegios, pues estos representaban una valoración distinta de los seres humanos, que se basaba, simplemente, en las circunstancias de su nacimiento e identificó la generalidad, abstracción e impersonalidad de las normas jurídicas con un derecho fundamental.

Esta visión formal del derecho a la igualdad primó durante muchos años, sin embargo, sería en Estados Unidos de Norteamérica (Rotunda y Nowak, 1992: 76 y ss.), que la cláusula de igual protección de los derechos ${ }^{4}$, identificada con el derecho a la igualdad, comenzara a mostrar un carácter material, especialmente en relación a la raza, para pasar desde allí al sistema internacional de los derechos humanos y, desde este último, al sistema continental europeo (Martín, 2003b: 200), donde la preocupación principal era el género (Bàrrere, 2014: 60).

Pese a entender que la XIVa Enmienda, donde está contenida la cláusula, solo obligaba al juez y el legislador estatal, y en consecuencia, su alcance era limitado, la sentencia Strauder v. West Virginia ${ }^{5}$ fue la primera en reconocer un contenido sustancial a la igualdad. Así, entendió que tal disposición «aseguraba a la raza recientemente emancipada y que había sido sometida durante muchas generaciones a la esclavitud, todos los derechos de los que goza la raza dominante». De esta manera, comienza a tomar forma la idea primitiva de que la igualdad no solo consistía en exigencias formales, sino que poseía una finalidad propia.

A decir verdad, la aplicación de dicha cláusula sufrió múltiples avances y retroceso ${ }^{6}$, sin embargo, valga mencionar que fue en el año 1886, en el caso Yick Wo v. Hopkins ${ }^{7}$, la primera vez que se interpretó la igualdad como prohibición al juez y al legislador estatal de establecer diferencias arbitrarias, afirmación que continúa vigente como uno de los posibles contenidos del derecho a la igualdad e inclusive de la no discriminación ${ }^{8}$.

En el derecho internacional, la forma de entender el derecho a la igualdad también fue variando. Así, las primeras prohibiciones de discriminación se remontan, en el ámbito internacional, a la Carta de las Naciones Unidas de 1945 y a la Declaración Universal de los Derechos Humanos del año 1948. Con

$4 \quad$ La XIVa Enmienda, en su parte pertinente, señala: «Ningún Estado podrá privar a alguna persona de su vida, libertad o propiedad sin un debido proceso legal; ni denegar a quienes se encuentren dentro de sus límites jurisdiccionales la igual protección de las leyes». 100 U. S.303 de 1878.

Sobre el particular puede consultarse Martín (2003a: 151 y ss.).

118. U. S.356.

8 Se volverá sobre este punto al abordar específicamente el derecho a no ser discriminado/a en Chile. 
todo, sería recién en el año 1958, a través del Convenio 111 de la OIT, que tal fenómeno tuviese su primera definición normativa aplicable al contexto del empleo 9 . Con posterioridad se hizo frecuente la incorporación a tratados internacionales generales y Constituciones de cláusulas expresas de no discriminación, así como la adopción de disposiciones internas que la proscribían de manera sectorial.

Aunque la proscripción de la discriminación poco a poco fue adquiriendo un carácter independiente del derecho a la igualdad, este origen derivado, así como su forma de protección, ha ocasionado que se produzca una diversidad de opiniones en relación a si igualdad y no discriminación son derechos o principios autónomos o simplemente la no discriminación es una parte o reinterpretación del derecho a la igualdad ${ }^{10}$, esta decisión puede resultar determinante a la hora de dilucidar el contenido de la no discriminación. Lo anterior se debe a que de ser principios autónomos podrían perfectamente contenidos distintos, como, por ejemplo, que el derecho a la igualdad fuese entendido en su sentido formal, mientras que la no discriminación podría asumir la labor de proteger a la población de tratos odiosos que se basen o que perjudiquen de manera desproporcionada a personas pertenecientes a ciertos colectivos. Por el contrario, si se sostiene que la no discriminación es una reinterpretación de la igualdad, se deberá preferir solo una noción que resulte inclusiva de todos los contenidos posibles.

\section{LAS DEFINICIONES DE LA DISCRIMINACIÓN Y SUS ELEMENTOS}

Rabossi (1990: 181 y ss.) entiende que en las consagraciones internacionales de la no discriminación es posible observar cuatro «bandas definicionales». Así, la primera se refiere a los tipos de actos que característicamente pueden causar discriminación, utilizando verbos como «excluir, distinguir o preferir», "limitar o restringir»; la segunda son aspectos, propiedades o cualidades que «juegan un papel fundamental» al momento de discriminar, los denomina "criterios críticos», tales como el sexo, la raza, lengua, opiniones políticas, entre otras; la tercera banda

9 Convenio 111 OIT: «Artículo 1

1. A los efectos de este Convenio, el término discriminación comprende:

(a) cualquier distinción, exclusión o preferencia basada en motivos de raza, color, sexo, religión, opinión política, ascendencia nacional u origen social que tenga por efecto anular o alterar la igualdad de oportunidades o de trato en el empleo y la ocupación;

(b) cualquier otra distinción, exclusión o preferencia que tenga por efecto anular o alterar la igualdad de oportunidades o de trato en el empleo u ocupación que podrá ser especificada por el Miembro interesado previa consulta con las organizaciones representativas de empleadores y de trabajadores, cuando dichas organizaciones existan, y con otros organismos apropiados».

10 Según se verá, de este origen y protección conjunta es también posible derivar que, en Chile, la forma de entender la discriminación coincida, en gran medida, con la igualdad formal. 
se integra por los objetivos o finalidades discriminatorios que se persiguen, lo que no implica, necesariamente, que exista una intencionalidad directa de discriminar, sino que, en los hechos, se produzca tal resultado y, por último, la cuarta intenta precisar las esferas en las cuales la discriminación tiene lugar, como, por ejemplo, el empleo, la educación o la política.

Ahora bien, la discriminación puede ser entendida, de acuerdo a su finalidad última de resguardar el igual valor intrínseco del ser humano, como «un trato igual o distinto basado en el prejuicio que sufren personas pertenecientes a ciertos grupos sociales y que ocasiona, o puede producir una privación del goce de ciertos derechos» (Esparza-Reyes, 2018a: 36).

La descripción anterior deja en evidencia la necesaria concurrencia de dos elementos: la existencia de una actitud odiosa o de prejuicio y la pertenencia a un colectivo tradicionalmente preterido o un grupo social subordinado ${ }^{11}$. Pese a que no todos los autores están de acuerdo con estos componentes (v. gr. Suay, 1985: 54 y ss.), existen fuertes razones para sostener su incorporación al concepto de discriminación. El primer motivo está constituido por la finalidad de la consagración del derecho a la igualdad, la que consistía en la eliminación de privilegios que, en último término, implicaba considerar más y menos valiosas a personas por su sola pertenencia a determinados colectivos. Además de lo anterior, hoy en día resultan habituales, tanto en los ordenamientos jurídicos internos cuanto regionales y universal, la incorporación de cláusulas específicas de no discriminación. Estas cláusulas señalan características por las cuales, tradicionalmente, se ha discriminado o se ha privado de derechos a ciertos grupos de personas. De esta forma, las cláusulas específicas de no discriminación deben ser entendidas como un reconocimiento de que históricamente existen personas que han sido minusvaloradas, excluidas, a través de la privación de sus derechos, por su sola pertenencia a ciertos colectivos (Serra, 2013: 15) ${ }^{12}$.

Por otra parte, además de estos motivos históricos y teleológicos, entender que la no discriminación posee un componente de grupo y de odiosidad o prejuicio resulta consistente con la existencia de la discriminación indirecta, que puede manifestarse en una disposición jurídica o comportamiento que, siendo aparentemente neutro, genera consecuencias desiguales perjudiciales debido al impacto diferenciado y desfavorable entre los distintos grupos involucrados (Rey, 2010: 537). De esta forma, para su reconocimiento se requiere de este componente

11 En un sentido similar Rey (2017: 128). Es también factible unir ambos requisitos entendiendo que la pertenencia a un grupo social preterido lleva, necesariamente, aparejada la existencia de un prejuicio u odiosidad sobre tal colectivo.

12 De manera deliberada se ha abordado la discriminación desde la concurrencia de una sola pertenencia que la provoque, es decir, se ha omitido referirse a la discriminación múltiple, compuesta o intersectorial, en las cuales, grosso modo, concurre más de una pertenencia o «causa» de discriminación (Rey, 2008: 263 y 264). Lo anterior se debe, simplemente, a motivos de claridad de la exposición y a que las respuesta frente a esta clase de situaciones, en varios casos, deben ser diferentes a las tradicionales (Serra, 2013: 41) 
grupal, en cuanto el impacto diferenciado no se considera en términos individuales, sino entre colectivos (Sierra, 2018: 17).

El reconocimiento de este elemento es consistente con la existencia de las acciones afirmativas ${ }^{13}$. Dentro de ellas, es posible incluir un sinnúmero de medidas que, en algunos casos, debido a que son muy diversas entre sí, pueden constituir afectaciones de los derechos fundamentales de otras personas ${ }^{14}$.

Estas acciones positivas, para resultar acordes con el sistema jurídico, es decir, constitucionales, requieren superar un test específico, el cual posee requisitos distintos dependiendo del lugar geográfico, pero en gran medida coincidentes, se trata del juicio o test de igualdad en sus distintos escrutinios, así como el test de razonabilidad ${ }^{15}$. Algunos de los requisitos propios de este test resultan sorteables de manera más sencilla si se considera que la no discriminación incluye los componentes de odiosidad, prejuicio y de grupo. Así, entender que la finalidad de la adopción de medidas de acción positiva es la terminación de discriminaciones sistemáticas contra grupos históricamente excluidos, resulta un fin legítimo, pero, además, tales elementos colaboran aclarando los criterios de categorización entre quienes se beneficiarán y quienes no con la medida, por cuanto, que sean personas que pertenecen a grupos sociales, entrega un criterio sencillo y aprehensible de distinción. De igual manera, estos dos componentes resultan relevantes, pues se ha estimado que las acciones afirmativas deben, necesariamente, tener por finalidad erradicar actos discriminatorios sistemáticos y colectivos, no individuales (Fabregat, 2009: 26).

La posibilidad de adoptar medidas de acción afirmativa, según se indicó, se fundamenta en la existencia de grupos sociales que han visto afectados sus derechos de manera persistente durante muchos años. Este fenómeno ha sido denominado

13 Estas pueden ser definidas como «todas aquellas medidas, diversas en sus manifestaciones, que tienen como destinatarios directos a personas que están o han estado discriminadas o que se hallan en una situación de desventaja estructural como consecuencia de su pertenencia a un cierto colectivo, pertenencia determinada por la posesión de algún rasgo completamente inmutable e íntimamente ligado, en tanto que definitorio de su identidad, a su dignidad como seres humanos, y que persiguen poner fin a esa situación de desventaja estructural, reducir los niveles de desigualdad entre dichos colectivos (y sus miembros) y el resto de la sociedad, y alcanzar mayores cotas de igualdad real dentro de la comunidad» (Martín, 2003b: 39 y 40).

14 En una escala ascendente de afectación, han sido tradicionalmente clasificadas en: acciones positivas moderadas, discriminación inversa racionalizada y discriminación inversa en estado puro (Giménez, 1999: 154 y ss). En otras ocasiones se ha dejado de manifiesto que acciones positivas y discriminaciones positivas son conceptos diametralmente distintos, puesto que estas últimas se establecen para supuestos concretos de discriminación (grupos sociales específicos); se dan en un contexto de especial escasez y se trata de discriminaciones directas (Rey, 2011: 179).

15 También es posible abordar este tema desde la perspectiva de los límites de las acciones positivas. En efecto, los primeros pronunciamientos a nivel europeo sobre la materia lo abordaron desde esta perspectiva, tales como los casos Kalanke y Marschall (Dema, 2008: 84). 
discriminación estructural, social o sistémica, pudiendo ser entendida como descripciones de la magnitud de un fenómeno contra ciertos colectivos (Courtis, 2006: 233) o como un fenómeno de dominación de un grupo social sobre otro, que se debe a las diferencias de poder existente entre ellos (Barrère 2003: 10). Así, el reconocimiento y erradicación de esta clase de conductas solo tiene sentido si se entiende que la discriminación posee un componente grupal, más allá de que sus manifestaciones puedan ser individuales, es decir, contra sujetos concretos.

La inclusión de la existencia de una actitud odiosa o de prejuicio y la pertenencia a un colectivo tradicionalmente preterido, como elementos de la discriminación, se hace todavía más patente en otra noción de la igualdad, la igualdad como no subordinación.

\section{LOS ELEMENTOS DE LA DISCRIMINACIÓN Y LA NO SUBORDINACIÓN}

La no subordinación ${ }^{16}$ o no exclusión surge como interpretación de la cláusula de igual protección de los derechos en Estados Unidos de Norteamérica. Su creador fue Owen Fiss (1976: 107 y ss.), quien, siguiendo las ideas de Mackinnon ${ }^{17}$, entendió que la sociedad, particularmente desde la perspectiva de la raza, se encontraba dividida en distintos grupos sociales, algunos de los cuales ocupan una situación de desventaja.

La postura de Fiss, que cuenta con seguidores en distintas latitudes ${ }^{18}$ con y sin variantes ${ }^{19}$, entiende que la igualdad persigue la eliminación de las subordinaciones, entendida como destrucción de las estructuras opresivas, en un sentido similar a lo planteado por Young (2000: 86 y ss.).

La no subordinación, aunque es similar a la no discriminación en varios aspectos, presenta importantes diferencias con ella (Esparza-Reyes, 2018a: 45 y ss.). Entre ellos valga mencionar: la no subordinación establece claramente cuál es su finalidad: terminar con las estructuras opresivas, mientras que, según se indicó, la falta de expresión de la finalidad de la no discriminación ha ocasionado que se confunda su plasmación concreta, generalmente como igual disfrute de derechos, con el fin perseguido. Por otra parte, la no subordinación entiende como un componente esencial la existencia de grupos sociales desaventajados, ello se debe a que son parte de su supuesto de existencia, a diferencia de lo que ocurre en la no discriminación, donde algunos autores, especialmente en Chile, no consideran como parte del concepto la pertenencia a grupos sociales o el prejuicio o

16 Se sigue en este punto a Esparza-Reyes (2018a: 45 y ss.).

17 Mackinnon es feminista y sostiene que existen importantes diferencias de poder entre hombres y mujeres, las cuales serían políticas (1995: 285 y ss.).

18 Por ejemplo, en Argentina destaca Roberto Saba (2016: 27 y ss.), quien ha dado forma a la desigualdad estructural en tal país.

19 Destaca a estos efectos el planteamiento de Barrère (Barrère y Morondo, 2011: 15 y ss.), cuya «subordiscriminación» es enormemente coincidente con la subordinación. 
trato odioso, sino que estiman que la discriminación puede consistir, simplemente, en un trato que carece de razonabilidad, que es caprichoso o que carece de justificación suficiente (Díaz de Valdés, 2017: 164). Por último, debido a la finalidad expresada por la no subordinación, las acciones positivas serían parte del derecho a la igualdad y no excepciones permitidas, como ocurre en la no discriminación, por lo que su adopción se facilita todavía más.

Por otra parte, es necesario indicar que la adopción de la no subordinación como contenido o reinterpretación del derecho a la igualdad no requeriría, necesariamente, de modificaciones a los textos legales, sino de la adopción, mediante la interpretación, de una noción de subordinación/discriminación, que considere esencial la protección de los derechos de las personas que pertenecen a grupos sociales oprimidos. En otras palabras, que incluya el componente grupal de tal fenómeno basado en la larga data de opresión que han sufrido las personas de tales grupos sociales, por el solo hecho de pertenecer a ellos.

La falta de claridad sobre el concepto de no discriminación adquiere características acentuadas en el caso chileno, donde lejos de la posibilidad de adoptar la no subordinación, la no discriminación presenta rasgos distintivos que alejan de la consideración a un elemento del grupo, según se verá.

\section{LA NO DISCRIMINACIÓN EN CHILE. LA CONVIVENCIA DE DISTINTAS NOCIONES DE DISCRIMINACIÓN ${ }^{20}$}

El desarrollo del principio de no discriminación en Chile se efectuó a través de la consagración del art. 19 № 2 de la Constitución Política de la República ${ }^{21}$, es decir, mediante el derecho a la igualdad, sin que en esta disposición se hubiesen incluido cláusulas específicas de no discriminación.

Producto de una interpretación "originalista» persistente de los preceptos constitucionales (Esparza-Reyes, 2018b: 153), la forma en que se entendió la discriminación durante muchos años fue exactamente la misma planteada por los comisionados encargados de redactar un proyecto de nueva Constitución en la década de los setenta ${ }^{22}$. Estos, agregando el adjetivo «arbitraria», la entendieron

20 Se seguirá en este punto, principalmente, lo planteado por Esparza-Reyes (2019: 3 y ss.)

21 "Artículo 19. La Constitución asegura a todas las personas:

$2^{\circ}$ La igualdad ante la ley. En Chile no hay persona ni grupo privilegiados. En Chile no hay esclavos y el que pise su territorio queda libre. Hombres y mujeres son iguales ante la ley.

Ni la ley ni autoridad alguna podrán establecer diferencias arbitrarias."

22 La Comisión de Estudio de la Nueva Constitución fue un órgano designado por la Junta Militar, durante la dictadura de Augusto Pinochet, para estudiar y proponer una nueva Carta Fundamental, la cual, con varias modificaciones por parte del Consejo de Estado y la Junta de Gobierno, fue sometida a plebiscito entró en vigor en el año 1980. Actualmente se mantiene vigente en Chile, aunque ha sufrido múltiples reformas. 
como acto carente de razonabilidad, caprichoso, sin justificación o injusto ${ }^{23}$, irracional, ilegal o fundado en la sola voluntad de un funcionario (Huepe, 2018: 211 y ss. $)^{24}$, es decir, obedeciendo a una lógica eminentemente formal, sin que resulte esencial el componente grupal para que se configure la discriminación.

En términos generales, es consistente entender que los actos arbitrarios en sentido amplio pueden vulnerar el derecho a la igualdad ${ }^{25}$, piénsese a estos efectos en la arbitrariedad de distinguir en base al color de los ojos para el otorgamiento de becas, que es también un atentado contra el derecho a la igualdad. Sin embargo, según se ha evidenciado de manera constante, la discriminación posee un desvalor adicional, el cual, en esta noción, se pone al mismo nivel que una arbitrariedad.

Por otra parte, la incorporación de múltiples tratados internacionales sobre derechos humanos al ordenamiento jurídico, los cuales suelen contener cláusulas específicas de no discriminación, hizo variar en algo el panorama entre la doctrina y la jurisprudencia, puesto que incorporó el elemento grupal ${ }^{26} \mathrm{y}$ de odiosidad a la discriminación, empero, según se verá, sería el inicio de la coexistencia de dos formas de entender la discriminación que conviven actualmente y que, en algunos casos, pueden resultar incompatibles entre sí, especialmente, si se considera que la igualdad y la no discriminación son un solo principio, es decir no autónomos.

La evolución posterior presentó avances y retrocesos, así la Ley 19.253 en el año 1993 en materia indígena; la Ley 20.422 de 2010 sobre inclusión de personas con discapacidad y el art. $2^{\circ}$ del Código del Trabajo, mediante la reforma

23 La adición de la «arbitrariedad» a la discriminación podría deberse a que se ha entendido la discriminación solo como una distinción en sentido neutro (Zúñiga, 2002: 237 y ss.). Es posible visualizar una evolución histórica en la noción de discriminación desde una forma "neutra» hasta una que considera la odiosidad como un elemento constitutivo de la misma (Díaz, 2015: 75).

24 Como es sabido, la interdicción de la arbitrariedad es un principio referido, principalmente, al ámbito administrativo. En este sentido se ha asentado el criterio de que obliga a los poderes públicos a la adopción de decisiones razonables o «no contrarias a la razón» (Fernández, 1999: 157 y 158).

25 Este hecho fue afirmado, también, por Leibholz, quien entendió que la proscripción de la arbitrariedad era la vinculación del legislador y la Administración al principio de igualdad (García de Enterría, 1959: 131).

26 Prueba de lo anterior son las definiciones de discriminación de diversos tratados y organismos internacionales, en las cuales, habitualmente, se señala que la discriminación se basa en pertenencias a grupos sociales, detallándolas. Solo a modo de ejemplo el Comité de Derechos Humanos del Pacto Internacional de Derechos Civiles y Políticos define la discriminación como «toda distinción, exclusión, restricción o preferencia que se basen en determinados motivos, como la raza, el color, el sexo, el idioma, la religión, la opinión política o de otra índole, el origen nacional o social, la propiedad, el nacimiento o cualquier otra condición social, y que tengan por objeto o por resultado anular o menoscabar el reconocimiento, goce o ejercicio, en condiciones de igualdad, de los derechos humanos y libertades fundamentales de todas las personas». 
introducida por la Ley 19.759 de 2001, basaron sus definiciones de discriminación en este componente grupal y de odiosidad de la discriminación.

En el año $2012^{27}$ se adoptó la Ley 20.609 que Establece Medidas contra la Discriminación. Esta norma jurídica consagró ciertas obligaciones estatales en materia de no discriminación, modificó algunas disposiciones legales, creó un procedimiento judicial específico en caso de vulneración y entregó una definición de discriminación:

Artículo $2^{\circ}$. - Definición de discriminación arbitraria. Para los efectos de esta ley, se entiende por discriminación arbitraria toda distinción, exclusión o restricción que carezca de justificación razonable, efectuada por agentes del Estado o particulares, y que cause privación, perturbación o amenaza en el ejercicio legítimo de los derechos fundamentales establecidos en la Constitución Política de la República o en los tratados internacionales sobre derechos humanos ratificados por Chile y que se encuentren vigentes, en particular cuando se funden en motivos tales como la raza o etnia, la nacionalidad, la situación socioeconómica, el idioma, la ideología u opinión política, la religión o creencia, la sindicación o participación en organizaciones gremiales o la falta de ellas, el sexo, la maternidad, la lactancia materna, el amamantamiento, la orientación sexual, la identidad de género, el estado civil, la edad, la filiación, la apariencia personal y la enfermedad o discapacidad. (las cursivas son nuestras) ${ }^{28}$.

La definición de discriminación contenida en la Ley Zamudio, como popularmente se conoce a esta disposición, presenta una importante característica que influirá en todo el sistema jurídico, a saber, incorpora los elementos de grupo social y prejuicio u odiosidad mediante una cláusula específica de no discriminación, que describe distintos grupos sociales preteridos, aunque deja abierto el catálogo, pero, al mismo tiempo, mantiene la arbitrariedad como criterio para configurar la discriminación. Aunque los autores no lo señalan expresamente, de sus análisis es posible extraer la primacía de la arbitrariedad y/o igualdad formal en desmedro del elemento grupal a la hora de definir la discriminación (v. gr. Díaz de Valdés, 2019: 60 y ss.).

27 El motivo inmediato de dicha ley fue el impacto ocasionado por el homicidio cometido contra el joven Daniel Zamudio Vera, de 24 años, quien falleció debido a un ataque homofóbico, perpetrado por cuatro sujetos, en la ciudad de Santiago de Chile.

El artículo continúa: «Las categorías a que se refiere el inciso anterior no podrán invocarse, en ningún caso, para justificar, validar o exculpar situaciones o conductas contrarias a las leyes o al orden público.

Se considerarán razonables las distinciones, exclusiones o restricciones que, no obstante fundarse en alguno de los criterios mencionados en el inciso primero, se encuentren justificadas en el ejercicio legítimo de otro derecho fundamental, en especial los referidos en los números $4^{\circ}, 6^{\circ}, 11^{\circ}, 12^{\circ}, 15^{\circ}, 16^{\circ}$ y $21^{\circ}$ del artículo 19 de la Constitución Política de la República, o en otra causa constitucionalmente legítima». 
La primacía de la arbitrariedad en la configuración de la discriminación, pese a que no se comparte, puede sostenerse en base a distintos argumentos. Los primeros de ellos son meramente gramaticales. Así, el primero es que el nombre utilizado para referirse a la discriminación es, precisamente, discriminación arbitraria, circunstancia que denotaría la importancia de tal noción en la de discriminación. El segundo, por su parte, es que el mismo artículo $2^{\circ}$ de la Ley 20.609 indica que la discriminación sería, justamente, una «distinción, exclusión o restricción que carezca de justificación razonable... en particular cuando se funden en motivos tales como...», es decir, describe la conducta, basándose en su arbitrariedad. A mayor abundamiento, al señalar «en particular cuando se funden» está indicando que es factible que existan casos de discriminación que no se basen en tales criterios.

Evidentemente, la asimilación entre la discriminación y la arbitrariedad genera discrepancias con la forma en que la doctrina mayoritaria de los sistemas internacional y europeo, entre los que se cuenta el español, ha entendido la discriminación, pero no solo eso, pues, según se indicó, coexisten en la normativa nacional diversos conceptos de discriminación que pueden ser alegados en sedes judiciales diferentes. De esta forma, para parte importante de la doctrina ${ }^{29}$, la discriminación arbitraria descrita en el artículo $2^{\circ}$ de la Ley 20.609 no incorporaría el elemento grupal (Díaz de Valdés, 2017: 451), afirmación que también comparte la jurisprudencia y que se evidencia, además, en que en un estudio desde la entrada en vigencia de la ley hasta el año 2017, el 15\% de las demandas judiciales ingresadas por vulneración de dicha disposición e independientemente de los resultados, no invocó ninguna de estas pertenencias (Díaz de Valdés, 2018: 21 y 23$)$.

Desde esta perspectiva, existirían al menos dos nociones de discriminación: una formal que la configura a través de la arbitrariedad, identificando ambos conceptos y otra de carácter material y concordante con los instrumentos internacionales de derecho antidiscriminatorio, que exige la consideración a un grupo social preterido para definir la discriminación.

Esta coexistencia de dos nociones dentro del mismo sistema jurídico genera consecuencias un tanto perniciosas, entre las que destaca la falta de estándares claros para jueces y juezas a la hora de resolver los casos de discriminación. Desde esta perspectiva, es posible observar en procedimientos tramitados de acuerdo a la Ley 20.609, sentencias en las cuales, siguiendo la doctrina mayoritaria (Díaz de Valdés, 2018: 20 y ss.), no se ha exigido para la configuración de la discriminación la pertenencia a un grupo social preterido y, por el contrario, otras en las que se ha estimado que tal elemento es esencial (Rol 26.206-2012 del $15^{\circ}$ Juzgado Civil de Santiago, Rol 407-2015 del Tercer Juzgado Civil de Concepción, Rol

29 En un sentido contrario, entendiendo que el art. 20 de la Ley 20.609 sí incorpora un elemento de perjuicio para un grupo «socialmente victimizado», Muñoz (2013: 211). 
5.058-2015 del Tercer Juzgado de Letras de La Serena) ${ }^{30}$, siendo relevante esta exigencia en tanto esta normativa no establece legitimaciones objetivas o abiertas (acción popular o de clase) ni tampoco otorga legitimación a un grupo como tal para interponer la acción (Rosales, 2014: 263).

Ahora bien, la noción de discriminación como arbitrariedad tiene, a su vez, efectos complejos y en ocasiones perjudiciales. En primer término, se relativiza el desvalor de la discriminación (Esparza-Reyes, 2019: 17), esto quiere decir que se invisibiliza el mayor grado de lesividad de una conducta que perjudica a las personas por su sola pertenencia a ciertos colectivos, poniéndolos al mismo nivel que, por ejemplo, medidas que no son proporcionadas. Esta mayor lesividad o desvalor es factible de sostener en base a la estrecha relación entre discriminación y dignidad humana, en cuanto esta última supone un igual valor de todos los seres humanos. Lo anterior, en ningún caso pretende excluir de protección las conductas que dañan a otras personas por ser caprichosas, irrazonables o carentes de fundamento, sino indicar que ellas no deben ser asimiladas conceptualmente a la discriminación.

Por otra parte, la noción de discriminación entendida como arbitrariedad no colabora con la adopción de medidas de acción afirmativa, al contrario de lo que ocurre con la discriminación que sí considera el elemento grupal. Lo anterior se debe a varios motivos: en primer término, puesto que es posible que en algunos casos, debido a la situación fáctica en la que se encuentran determinados grupos sociales, la adopción de tales medidas resulte obligatoria, es decir, no solo aceptada constitucionalmente, sino exigida. Serán los casos en que tales colectivos evidencien situaciones de especial sometimiento, como, por ejemplo, violencia. En segundo lugar, y en relación al test de razonabilidad, existen dos diferencias entre la adopción de una u otra noción. Así, la sola existencia de grupos que se encuentran en una situación desaventajada resulta una finalidad plausible para la adopción de medidas de acción afirmativa, mientras que, si se sostiene que la discriminación consiste en la no arbitrariedad, será necesario realizar un análisis más exhaustivo y difícil de sortear. Lo mismo ocurre respecto de la correcta categorización o criterio de razonabilidad que deben sortear las acciones positivas, en cuanto la identificación de estos grupos sociales preteridos colabora con que se realice de manera acertada en los casos que se pretenda beneficiarles.

En último término, pero de la mayor importancia, la adopción de la arbitrariedad como criterio definitorio de la discriminación produce conflictos de compatibilidad con los estándares internacionales de no discriminación, los cuales, efectivamente, consideran el elemento de grupo desaventajado en su configuración, y que, debido a ello, en algunos casos, obligan a emprender acciones estatales para luchar contra la discriminación.

30 Se puede encontrar un análisis cuantitativo en relación a estas causas en el texto de Díaz de Valdés (2018: 15 y ss.). 


\section{MECANISMOS DE PROTECCIÓN DE LA NO DISCRIMINACIÓN EN CHILE. BREVE PANORAMA GENERAL}

El derecho a no sufrir discriminación en Chile posee múltiples mecanismos de protección. Así, podemos encontrar mecanismos que tienen por finalidad directa terminar con la discriminación, como la prohibición de discriminación en el consumo establecido en la Ley 19.496 de Protección de los Derechos de los Consumidores, o mecanismos que no poseyendo tal objetivo colaboran con él, tal como la obligatoriedad de que en las listas electorales se incorporen mujeres que se estableció a través de la Ley 20.840. También existen mecanismos que contemplan un procedimiento judicial como el establecido en la Ley 20.609, o que carecen de él, como la Ley 20.820, que crea el Ministerio de la Mujer y Equidad de Género. Junto a ellas, coexisten iniciativas públicas, como la eliminación de disposiciones legales discriminatorias, e iniciativas privadas, como las acciones positivas que adoptan algunas empresas. Además de mecanismos que combaten la discriminación en ámbitos determinados, como la prohibición de discriminación en materia laboral establecida en el art. $2^{\circ}$ del Código del Trabajo o en términos generales como la prohibición de discriminación establecida en la Ley 20.609, mecanismos, todos, que pueden encontrarse en tratados internacionales, la Constitución, leyes o normas infralegales.

De este modo, Chile contempla múltiples disposiciones, con diversas características, que tienen como objetivo combatir la discriminación y, tal como se indicó anteriormente, no todas configuran la discriminación considerando como esencial el elemento grupal. Sin embargo, destacan a estos efectos tres disposiciones normativas que sí incorporan tal elemento.

La primera de ellas es el art. $8^{\circ}$ de la Ley 19.253 que establece normas sobre protección, fomento y desarrollo de los indígenas, y crea la Corporación Nacional de Desarrollo Indígena; la segunda es el art. $6^{\circ}$ de la Ley 20.422 que establece normas sobre igualdad de oportunidades e inclusión social de personas con discapacidad, mientras que la tercera es el art. $2^{\circ}$ del Código del Trabajo.

La Ley 19.253 se adoptó en el año 1993, en ella se contempla como falta la discriminación contra indígenas en su calidad de tales, y la define ${ }^{31}$. Tal definición no resulta consistente con los estándares internacionales actuales, en cuanto exige para su configuración que la acción discriminatoria se realice en base al «origen o cultura» de los indígenas y que sea «manifiesta o intencionada", imponiendo requisitos de muy difícil prueba. Probablemente debido a lo anterior, ha tenido escasísima o nula aplicación.

31 «Artículo $8^{\circ}$. - Se considerará falta la discriminación manifiesta e intencionada en contra de los indígenas, en razón de su origen y su cultura. El que incurriere en esta conducta será sancionado con multa de uno a cinco ingresos mínimos mensuales.» 
La Ley 20.422, por su parte, entró en vigor en el año 2010 y en su art.

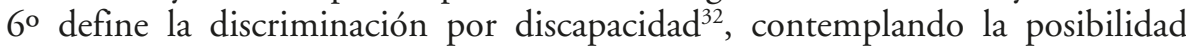
de solicitar indemnización de perjuicios por su ocurrencia. Destaca en esta definición la completa adecuación a estándares internacionales, ello pese a que incorpora, nuevamente, el elemento de arbitrariedad. Esta alusión a la arbitrariedad no le transforma en definitoria del acto, pues considera que dicho acto arbitrario debe fundarse en la discapacidad, teniendo como fin o simple resultado la afectación del goce o ejercicio de los derechos. En este sentido, puede decirse que se trata de la definición de origen nacional que más cerca está de lo señalado por la doctrina comparada y los organismos internacionales de protección de los derechos humanos.

El Código del Trabajo, en tanto, en su art. $2^{\circ}$, señala que los actos de discriminación son contrarios a los principios de las leyes laborales y entrega una definición de discriminación aplicable en dicho ámbito ${ }^{33}$. Tal definición y su aplicación resulta interesante por varios motivos, a saber: en primer término, porque exige intencionalidad, pero esta intencionalidad debe tener por objeto anular o alterar la igualdad de oportunidades o de trato en el empleo o la ocupación, no coincidiendo con los tratados internacionales generales, pero sí con el Convenio 111 de la Organización Internacional del Trabajo (OIT) ${ }^{34}$.

En segundo término, esta definición sí incluye pertenencias a grupos sociales preteridos, realizando una enumeración que no considera una cláusula de apertura, es decir, carece de una disposición que indique «o cualquier otra condición», como suele ocurrir en otros textos. A mayor abundamiento, en el año 2016, mediante la Ley 20.940 se incorporaron nuevas pertenencias, sin que se modificase la ausencia de una cláusula de apertura. Con todo, y pese a la letra del mismo artículo, tanto la doctrina ${ }^{35}$ cuanto la jurisprudencia ${ }^{36}$ han indicado que las pertenencias señaladas en el art. $2^{\circ}$ no serían taxativas, ello debido a una

32 «Artículo 6º - Para los efectos de esta ley, se entiende por:

a)Discriminación: Toda distinción, exclusión, segregación o restricción arbitraria fundada en la discapacidad, y cuyo fin o efecto sea la privación, perturbación o amenaza en el goce o ejercicio de los derechos establecidos en el ordenamiento jurídico.»

33 Art. $2^{\circ}$ inciso 4: «Los actos de discriminación son las distinciones, exclusiones o preferencias basadas en motivos de raza, color, sexo, edad, estado civil, sindicación, religión, opinión política, nacionalidad, ascendencia nacional, situación socioeconómica, idioma, creencias, participación en organizaciones gremiales, orientación sexual, identidad de género, filiación, apariencia personal, enfermedad o discapacidad u origen social, que tengan por objeto anular o alterar la igualdad de oportunidades o de trato en el empleo y la ocupación».

34 Resulta necesario aclarar que esta Convención no exige, para configurar la discriminación, que esta sea intencionada, sino que solo indica que se requiere el efecto de anular o alterar la igualdad de oportunidades o de trato en el empleo y la ocupación.

35 En este sentido, por ejemplo, Ugarte (2013: 1) y Gamonal (2014: 63 y 64).

36 Este criterio se consolidó a través del Recurso de Unificación de Jurisprudencia en materia laboral resuelto por la Corte Suprema, Rol 23.808 de 5 de Agosto de 2015. 
interpretación sistemática acorde con el art. 1916 de la Constitución Política, que prohíbe la discriminación en el ámbito laboral, sin entregar una definición. Lamentablemente, esta extensión, aunque entrega mayor protección, remite nuevamente a la arbitrariedad para configurar la discriminación, puesto que utiliza la noción constitucional.

El mecanismo jurisdiccional de protección del derecho a no ser discriminado/a, en materia laboral, es el procedimiento de tutela de derechos fundamentales. Este procedimiento permite, de acuerdo al art. 4953 del Código del Trabajo, la obtención de una indemnización de perjuicios, aunque ello no es la única particularidad, puesto que también indica que en casos de despido injustificado por discriminación "grave», el trabajador puede optar entre las indemnizaciones y la reincorporación (Gamonal, 2016: 307). Respecto de los criterios para calificar de "grave» una discriminación no existe acuerdo, pudiendo referirse a la utilización de alguna de las pertenencias indicadas expresamente o a los efectos de la discriminación.

En el siguiente epígrafe se analizarán otras dos acciones de justicia constitucional que protegen de la discriminación. Tal como se indicó anteriormente, la elección metodológica se debe a que se trata de mecanismos generales, no para un ámbito privativo o exclusivo, como puede ser el consumo o el ámbito laboral, pero, además, debido a que se trata de los mecanismos más extendidos y utilizados para proteger el derecho a no ser discriminado/a en Chile, haciendo ambos referencia explícita en su objetivo a la protección del derecho establecido en el art. 192 de la Constitución.

\section{LA ACCIÓN DE PROTECCIÓN Y LA ACCIÓN DE NO DISCRIMINACIÓN ARBITRARIA}

\section{ASPECTOS GENERALES}

La Ley 20.609, que Establece Medidas contra la Discriminación, fue publicada en el Diario Oficial el 24 de julio de 2012, después de siete años de tramitación legislativa sufriendo en ese tiempo múltiples modificaciones el proyecto original. La ley consta de tres títulos, en el primero se contiene el propósito de la norma y una definición de discriminación arbitraria. El segundo título establece una acción y un procedimiento especial cuyo fin es combatir los actos de discriminación arbitraria, regulando su tramitación y aspectos procesales. El título tercero introduce modificaciones al Estatuto Administrativo, al Estatuto Administrativo para Funcionarios Municipales y al Código Penal, reformando su contenido a través de la proscripción de la discriminación arbitraria.

Por su parte, la Acción de Protección es un mecanismo de tutela de los derechos fundamentales asegurados a todas las personas en el art. 19 de la Constitución Política. El art. 20 de la Carta Fundamental establece esta acción tutelar 
respecto de actos u omisiones arbitrarias o ilegales que causen privación, perturbación o amenaza en el legítimo ejercicio de los derechos y garantías que asegura el art. 19, entre los cuales se encuentra, en el numeral $2^{\circ}$, el derecho a la igualdad. Sin embargo, el procedimiento para la tramitación de esta acción no se encuentra en la propia Constitución ni en la ley, sino que, ante el vacío de la norma fundamental a este respecto, fue regulado a través de un auto acordado de la Corte Suprema, el cual ha sido objeto de diversas críticas debido a las consecuencias que esta regulación infralegal genera.

\section{ASPECTOS PROCEDIMENTALES RELEVANTES DE LA ACCIÓN DE NO DISCRIMINACIÓN ARBITRARIA Y LA ACCIÓN DE PROTECCIÓN}

A continuación se analizarán determinados aspectos procesales relevantes de ambas acciones de justicia constitucional que buscan combatir la discriminación, con el fin de contrastarlas en cuanto a su influencia en la determinación del concepto de discriminación y en la protección del derecho a no ser discriminado/a.

Respecto de la acción especial de no discriminación arbitraria, la ley Zamudio (20.609) en su art. $2^{\circ}$, establece que aquella procede contra las conductas que reúnan tres elementos copulativos (Rosales, 2014: 279 y ss.), a saber: que se trate de una distinción, exclusión o restricción que sea efectuada por agentes del Estado o por particulares; que tal conducta carezca de justificación razonable, y que cause privación, perturbación o amenaza en el ejercicio legítimo de los derechos fundamentales establecidos en la Constitución o en los tratados internacionales sobre derechos humanos ratificados por Chile y que se encuentren vigentes.

En cuanto al primer elemento, la Ley 20.609 utiliza verbos que involucran acciones, dejando aparentemente fuera de la norma las conductas de omisión, elección lingüística que acarrea diversas problemáticas, especialmente de índole probatoria. Sin embargo, la doctrina y jurisprudencia se encuentran contestes que tales conductas sí incluyen a las omisiones (Farías, 2014: 74 y ss.), debido a que el art. $5^{\circ}$ de la Ley 20.609 , al regular el plazo y forma de interposición de la acción, hace referencia expresa a conductas de omisión. Por otra parte, y al contrario, el art. 20 de la Constitución Política que establece la acción de protección, contempla expresamente las omisiones.

Del mismo modo, dichas acciones pueden ser realizadas, indistintamente, por el Estado o por los particulares, plasmando de modo expreso el efecto horizontal del derecho a igualdad y no discriminación (Gauché, 2014: 38 y ss.), cuestión que ya había sido incorporada al ordenamiento jurídico por la doctrina y la jurisprudencia, a través de la interpretación extensiva del art. 192 de la Constitución (Díaz de Valdés, 2018: 23 y ss.) a casos concretos de relaciones entre particulares en diversos ámbitos, tales como como el derecho del trabajo, derechos de los consumidores y derecho educacional. 
El segundo requisito, y de la mayor relevancia, pues refuerza la exigencia de arbitrariedad, es la ausencia de justificación razonable. Tal como se indicó anteriormente, un inciso posterior agrega que:

Se considerarán razonables las distinciones, exclusiones o restricciones que, no obstante fundarse en alguno de los criterios mencionados en el inciso primero, se encuentren justificadas en el ejercicio legítimo de otro derecho fundamental, o en otra causa constitucionalmente legítima (art. $2^{\circ}$, inciso final).

A continuación, menciona expresa y especialmente los derechos a la vida privada y la honra de las personas, la libertad de conciencia, la libertad de enseñanza, la libertad de emitir opinión y de informar, el derecho de asociación, la libertad de trabajo y el derecho a desarrollar cualquier actividad económica. Esta disposición ha sido objeto de múltiples reparos, aclarándose que será labor del juez la resolución de los conflictos de derechos que puedan presentarse y que no se trata de una enumeración taxativa, pudiendo justificarse la discriminación arbitraria en otro derecho fundamental reconocido por la Constitución o los tratados internacionales ratificados por Chile, si logra acreditarse su justificación a través de la prueba (Rosales, 2014: 280; Farías, 2014: 95). Sobre este punto, parte de la doctrina ha sostenido que se trata de una redacción problemática, en tanto el derecho a no ser discriminado carecería de contenido si es que no se vincula a la vulneración de otro derecho fundamental, cuestionando su autonomía (Díaz, 2013: 642; Gauché, 2014: 39). Este último hecho, no resultaría consistente con lo establecido por la Constitución, pues la acción de protección del art. 20 no exige la vinculación con otro derecho (Díaz de Valdés, 2013: 283 y ss.). Algo similar ocurre con la fórmula de justificación de las conductas aparentemente discriminatorias en base a "otra causa constitucionalmente legítima", ya que la doctrina ha tenido que aclarar que se refiere a aquellos bienes o intereses de jerarquía constitucional, diversos de los derechos ya mencionados en el inciso primero, debiendo rechazarse la acción si se justifica el actuar del demandado alegando estas causas constitucionales.

Continúa el inciso primero del art. $2^{\circ}$, señalando que procederá esta acción especial, particularmente, cuando la o las acciones de discriminación se funden en motivos tales como la raza o etnia, la nacionalidad, la situación socioeconómica, el idioma, la ideología u opinión política, la religión o creencia, la sindicación o participación en organizaciones gremiales o la falta de ellas, el sexo, la orientación sexual, la identidad de género, el estado civil, la edad, la filiación, la apariencia personal y la enfermedad o discapacidad, entendiéndose que no se trata de una numeración taxativa (Díaz de Valdés, 2013: 280 y ss.). Tales categorías, indica la ley en el inciso segundo de este art. $2^{\circ}$, no podrán invocarse, en ningún caso, para justificar, validar o exculpar situaciones o conductas contrarias a las leyes o al orden público, concluyendo que, para la calificación de una acción como discriminatoria, no se hace referencia ni se debe indagar en la intención, la cual no sería relevante (Díaz de Valdés, 2013: 292). 
De la definición contenida en el artículo segundo de la Ley Zamudio es posible colegir que existe una diferencia en cuanto al momento en que se protege el derecho a no ser discriminado/a, debido a que la acción de protección protege de toda privación, perturbación o amenaza al derecho, de modo que puede operar como una protección preventiva, lo que no acontece en el caso de la acción especial de la Ley 20.609. Por su parte, la acción de protección establece que ella procederá frente a la privación, perturbación o amenaza de los derechos fundamentales que protege, siempre que aquella sea arbitraria o ilegal (Paredes, 2014: 123).

En cuanto a los aspectos procesales, la Ley 20.609 establece en su art. $3^{\circ}$, que conocerán de esta acción especial indistintamente, a elección del directamente afectado/a, el juez de letras de su domicilio o el del domicilio del responsable de la acción. Esta elección resulta cuestionable debido a que, los jueces de letras no tienen como competencia natural la protección de los derechos fundamentales de las personas, como sí la tienen las Cortes de Apelaciones competentes para conocer de la acción de protección hace más de veinte años. A esto debe agregarse que los principios procesales sobre los que se estructura la jurisdicción de los tribunales civil son diferentes a los de las Cortes de Apelaciones donde se encuentra radicado el conocimiento de la acción de protección, viéndose ambos procedimientos influidos por la forma que tienen el juez y las partes de participar en el proceso (Rosales, 2014: 260 y ss.). Así, rige en materia civil el principio dispositivo que dificulta que el juez tenga una participación activa y directa en el proceso, detentando el rol activo las partes, situación inversa rige para las Cortes de Apelaciones, donde las facultades inquisitivas y el rol activo del juez juegan un papel preponderante para la protección de los derechos fundamentales, unidas a la experiencia con la que ya contaban en esta materia derivada de las acciones de protección y amparo (Díaz de Valdés, 2013: 295).

Respecto de la legitimación activa para interponer la acción de no discriminación arbitraria, el art. $4^{\circ}$ de la Ley Zamudio establece que podrá deducirla cualquier persona lesionada en su derecho a no ser objeto de discriminación arbitraria, su representante legal o quien tenga de hecho el cuidado personal o la educación del afectado/a, circunstancia que deberá señalarse en la presentación. Agrega que también podrá deducirse por cualquier persona a favor de quien ha sido objeto de discriminación arbitraria, cuando se encuentre imposibilitado/a de ejercerla y carezca de representantes legales o personas que lo/a tengan bajo su cuidado o educación, o cuando, aun teniéndolos, se encuentren también impedidos/as de deducirla. Esta norma establece una legitimación activa específica para la acción especial de la Ley 20.609, lo que dista de la regulación de la acción de protección, donde la legitimación activa es amplísima, recayendo sobre cualquier persona, natural o jurídica, agrupaciones de personas y/o por interpósita persona sin mandato especial e, incluso, contra la voluntad del titular del derecho, de acuerdo al art. $2^{\circ}$ del auto acordado que regula su tramitación (Paredes, 2014: 127 y ss.).

La acción de no discriminación arbitraria deberá deducirse, de acuerdo al art. $5^{\circ}$ de la Ley Antidiscriminación, dentro de noventa días corridos contados desde la 
ocurrencia de la acción discriminatoria, o desde el momento en que el afectado/a adquirió conocimiento cierto de ella. Siguiendo lo señalado por este mismo art. 50, la acción deberá interponerse por escrito, pudiendo, en casos urgentes, interponerse verbalmente, levantándose acta por la secretaría del tribunal. Se establece, además, un plazo de un año de acontecido el acto para la caducidad de la acción. Por su parte, la acción de protección debe interponerse en un plazo de treinta días corridos desde que tuvo lugar la acción u omisión que supone la vulneración del derecho fundamental, justificándose este breve plazo por la urgencia de la tutela solicitada a través de ella. Sin embargo, en la práctica, las Cortes de Apelaciones suelen extender este plazo, renovándolo constantemente en casos de vulneraciones continuas o reiteradas o actos lesivos de efectos permanentes (Paredes, 2014: 126 y ss; Rosales, 2014: 263).

En cuanto al procedimiento, en el caso de la acción de protección de la Constitución, se trata de un procedimiento sumarísimo, con un contradictorio comprimido considerablemente, breve, concentrado y urgente, estructurado de manera desformalizada, concediéndole amplias facultades discrecionales a las Cortes de Apelaciones (Rosales, 2014: 265). Además, se trata de una acción principal, ya que no se requiere deducir otra acción de forma previa ni posterior $\mathrm{y}$, como se trata de una tutela de urgencia, deja subsistentes las acciones pertenecientes al derecho común y a la justicia ordinaria (Paredes, 2014: 124 y ss.), tales como la indemnización de perjuicios. Por su parte, la acción de no discriminación arbitraria de la Ley 20.609 es una acción especial, regulada minuciosamente que se desarrolla a través de un contradictorio extendido regido por el principio dispositivo, similar a un juicio sumario civil, con un llamado a conciliación obligatorio y petición de informes al/los demandados. Estos últimos han extendido el tiempo de tramitación de la acción, cuestionándose su establecimiento en torno a la garantía de un juicio sencillo y rápido y a las características de una acción de protección de derechos fundamentales (Rosales, 2014: 265). Además, esta acción es incompatible, por disposición expresa del art. $6^{\circ}$, con la Acción de Habeas Corpus, de Protección y de Tutela de Derechos Fundamentales en sede laboral, siempre que hayan sido declarados admisibles y, también, para impugnar leyes vigentes y sentencias anteriores (Coddou et al., 2013: 296 y ss.).

En cuanto a la prueba, se plasma en el art. $9^{\circ}$ que se realizarán audiencias para su ofrecimiento y rendición, admitiéndose una amplitud de medios de prueba (libertad de admisión), siempre que sea obtenida lícitamente y sirva para producir fe. En cuanto a su valoración, en ambos casos, el estándar de apreciación corresponde a las reglas de sana crítica. Sin embargo, en este apartado existe controversia en cuanto a si la Ley Zamudio alteró la carga de la prueba o estableció un sistema de prueba indiciaria como lo hace, por ejemplo, el procedimiento de tutela en sede laboral regulado por el Código del Trabajo. Se ha sostenido que la Ley Antidiscriminación no estableció ninguna regla especial respecto a la carga de la prueba, aplicándose la regla general establecida en el art. 1698 del Código Civil, que señala que incumbe probar los hechos a quien los alega, de modo que quien demanda debe acreditar los hechos que constituyen la discriminación arbitraria, existiendo un equilibrio en cuanto a la aportación de la prueba. Otros 
indican que las "categorías sospechosas» del art. 2 de la Ley 20.609 alterarían la carga de la prueba al establecerse como verdaderas presunciones. En la práctica se han aplicado las reglas generales, dificultando la prueba para este tipo de acciones, lo que no acontece en la acción de protección, en la cual solo extraordinariamente se rinde prueba, pues su tramitación se basa en informes, que, en cualquier caso, son prescindibles por las Cortes de Apelaciones.

Finalmente, respecto de las medidas que puede adoptar el tribunal en su sentencia, para el caso de la acción de discriminación arbitraria, de acuerdo al art. 12 de la Ley 20.609, el tribunal declarará si ha existido o no discriminación arbitraria, dejando sin efecto el acto discriminatorio, disponiendo que aquel no sea reiterado $\mathrm{u}$ ordenando que se realice el acto que ha sido omitido en su caso, y fijando un plazo perentorio para el cumplimiento de estas medidas. Además, el tribunal está facultado para aplicar una multa a beneficio fiscal, a las personas directamente responsables del acto discriminatorio. Al igual que la acción de protección de la Constitución, la acción especial de no discriminación establece que el tribunal podrá adoptar las demás providencias que considere necesarias para restablecer el imperio del derecho y asegurar la debida protección del afectado/a, presentando la misma redacción la Ley 20.609 y el art. 20 de la Constitución.

Debe agregarse que la tramitación de la acción de protección de la Constitución puede resultar más rápida, ya que puede resolverse el asunto sin solicitar mayores antecedentes a las partes, a través de informes $\mathrm{u}$ ordenando alguna diligencia probatoria o medida cautelar, cuyo requerimiento queda a criterio de las Cortes de Apelaciones. No siendo así para el caso de la acción especial de no discriminación, ya que, pese a que el art. $8^{\circ}$ de la Ley 20.609 establece que el tribunal puede prescindir de los informes que solicita, esto representa un problema probatorio frente a su tramitación en sede civil, vulerando los principios de bilateralidad de la audiencia e igualdad de armas (Farías, 2014: 84 y ss.). Además, en el caso de la acción de protección constitucional, nada impediría que el mismo asunto sea discutido nuevamente en un procedimiento ordinario, aunque concurra la triple identidad exigida por la cosa juzgada, en tanto la sentencia recaída en la acción de protección solo produce cosa juzgada formal, debido a que se trata de un procedimiento de urgencia, sin etapa probatoria y alejado del principio contradictorio, por lo que deja a salvo el derecho a discutir el fondo del asunto en un procedimiento de lato conocimiento (Paredes, 2014: 124 y ss.).

Así, existiendo similitudes entre ambas acciones en cuanto al procedimiento aplicable: examen de admisibilidad, petición de informes, función de restablecer el imperio del derecho y apreciación probatoria, es posible señalar que la acción establecida en la Ley 20.609, aunque entrega un mayor plazo para su interposición, restringe la interposición de otras acciones jurisdiccionales y es más gravosa (Farías, 2014: 81 y ss.). De esta forma, comparativamente, y desde una perspectiva procedimental, la acción de protección resguarda de manera más adecuada el derecho a no ser discriminado/a, ya que su estándar probatorio no ha sido cuestionado, presenta plazos de tramitación más breves y no posee plazos de caducidad de la acción. 


\section{CONCLUSIONES}

Las nociones de discriminación utilizadas en la Ley Zamudio y la acción de protección no varían en cuanto a sus elementos, pues ambas consideran esencial la existencia de arbitrariedad y carecen del elemento de grupo o de odiosidad o prejuicio hacia ellos. Sin embargo, el art. 192 de la Constitución Política, aunque no posee cláusulas específicas y su interpretación tradicional ha sido muy cercana, si no asimilable, a la igualdad formal, ostenta un grado alto de plasticidad debido a que no consagra una definición de discriminación. Esta circunstancia, unida a las obligaciones estatales de erradicar la discriminación en los términos de los tratados internacionales sobre la materia, le permite, y le invita, a incorporar, mediante la interpretación, el elemento de grupo, en los casos de discriminación tramitados a través de la acción de protección. En otras palabras, la consagración de la igualdad del art. 192 de la Constitución posee el potencial de incorporar este elemento grupal al concepto de discriminación, circunstancia que de la letra del art. 2 de la Ley 20.609 no es factible derivar.

La posibilidad anterior, es decir, la incorporación del elemento grupal, permitiría, a diferencia de lo que ocurre con el procedimiento judicial establecido en la Ley Zamudio, alegar en sede judicial, a través de la acción de protección, respecto de actos que se basan, precisamente, en este componente grupal de la discriminación. Uno de estos actos es la discriminación indirecta, en cuanto ella tiene sentido cuando se reconoce que existen fenómenos que generan consecuencias perjudiciales específicas, o mayormente lesivas, para ciertos grupos de personas que solo tienen en común la pertenencia a un colectivo preterido, pero, además, debido a que esta clase de discriminación puede no verse plasmada en distinciones, exclusiones o restricciones, sino, en algunos casos, en conductas aparentemente neutras o iguales.

Por otra parte, el reconocimiento de este elemento en la interpretación del art. 192 de la Constitución, permitiría accionar de protección en los casos de discriminación estructural. Ello se debe a que el art. 20 de la Constitución autoriza a interponer la acción de protección por actos u omisiones, en cambio, el art. $2^{\circ}$ de la Ley 20.609, solo indica que dicha acción procede respecto de distinciones, exclusiones o restricciones, no incorporando las omisiones de manera expresa sino a través de analogías y razonamientos que dificultan la prueba. Como se indicó con anterioridad, la discriminación estructural no necesariamente consiste en actos, sino que puede manifestarse en ellos, por cuanto se trata de fenómenos de dominación. De esta forma, si no existen actos concretos que evidencien la discriminación, sería posible accionar por la omisión de conductas que terminen con esta clase de discriminación, o al menos, entender que ella se sigue produciendo en el tiempo, aunque no se manifieste un hecho concreto, lo que podría modificar los plazos de caducidad de la acción. Esta posibilidad no es sostenible con la definición de la Ley 20.609 en dicho procedimiento judicial. 
En un sentido similar, la superación del test de razonabilidad de las acciones positivas resultaría más sencilla si se considera como parte de la discriminación el elemento grupal. Así, en caso de reclamarse mediante la acción de protección por la adopción de una medida de acción positiva, quien intente dejarla sin efecto sorteará mayores inconvenientes, en cuanto tales acciones tendrían una finalidad y una categorización apropiada.

Para finalizar, es necesario destacar que, actualmente, solo sería posible adoptar una interpretación de la igualdad como no subordinación, con las ventajas que ello implicaría, a través del art. 192 de la Constitución, y en consecuencia, alegable a través de la acción de protección, por cuanto, para la primera, el elemento de grupo social preterido resulta esencial.

\section{Bibliografía}

Barrère, M. A. (2003). Problemas de Derecho Antidiscriminatorio: Subordinación versus discriminación y acción positiva versus igualdad de oportunidades. Cuadernos Electrónicos de Filosofía del Derecho, 9, 1-26.

- (2014). El Derecho Antidiscriminatorio y sus limites, especial referencia a la perspectiva iusfeminista. Lima: Editorial Grijley.

Barrère, M. A. y Morondo, M. (2011). Subordiscriminación y discriminación intersectorial: elementos para una teoría del Derecho Antidiscriminatorio. Anales de la Cátedra Francisco Suárez. Igualdad u Derecho Antidiscriminatorio, 45, 16-42.

Coddou, A., Schönsteiner, J. y Vial, T. (2013). La ley antidiscriminación: avances e insuficiencias en la protección de la igualdad y la no discriminación en Chile. En T. Vial (ed.). Informe Anual sobre Derechos Humanos en Chile (pp. 285-309). Santiago de Chile: Ediciones Universidad Diego Portales.

Courtis, C. (2006). Legislación y las políticas antidiscriminatorias en México: el inicio de un largo camino. En C. de la Torre (coord.). Derecho a la no discriminación (pp. 231-262). México D.F.: Instituto de Investigaciones Jurídicas.

Dema, S. (2008). A la Igualdad por la desigualdad. La acción positiva como estrategia para combatir la discriminación de las mujeres. Oviedo: Ediciones KRK.

Díaz, I. (2013). Ley chilena contra la discriminación. Una evaluación desde los derechos internacional y constitucional. Revista Chilena de Derecho, 40 (2), 635668. Disponible en: https://doi.org/10.4067/S0718-34372013000200011.

Díaz de Valdés, J. M. (2013). ¿Es la Ley Zamudio verdaderamente una ley general antidiscriminación? Revista Actualidad Jurídica, 28, 279-297.

- (2017). Cuatro años de la Ley Zamudio: análisis crítico de su jurisprudencia. Revista de Estudios Constitucionales, 15 (2), 447-488. Disponible en: https://doi. org/10.4067/S0718-52002017000200447.

- (2018). Análisis cuantitativo de la acción especial antidiscriminación de la Ley Zamudio. Revista Actualidad Juridica, 38, 15-33.

- (2019). Igualdad constitucional y no discriminación. Valencia: Editorial Tirant lo Blanch. 
Díaz Revorio, F. J. (2015). Discriminación en las relaciones entre particulares. México D. F.: Tirant lo Blanch.

Esparza-Reyes, E. (2018a). La igualdad como no subordinación. Una propuesta de interpretación constitucional. México D. F.: Tirant lo Blanch.

- (2018b). La relación entre los problemas de legitimidad de la Constitución de 1980 y la utilización de mecanismos «originalistas» en su interpretación. En Asociación Chilena de Derecho Constitucional. Una Nueva Constitución para Chile (pp. 153-175). Santiago de Chile: Editorial Jurídica de Chile.

- (2019). Algunas reflexiones críticas sobre el derecho a la igualdad como no discriminación en Chile. Cuestiones Constitucionales: Revista Mexicana de Derecho Constitucional, 40, 3-37.

Fabregat, G. (2009). Las medidas de acción positiva. La posibilidad de una tutela antidiscriminatoria. Valencia: Tirant lo Blanch.

Farías, J. (2014). Los efectos procesales de la corrección política en el ordenamiento jurídico chileno con ocasión de la Ley 20.609. Revista Boni et Aequi, 11 (1), 67-99. Disponible en: https://doi.org/10.23854/07192568.2015111Farias67.

Fernández, T. R. (1999). De la arbitrariedad de la administración. Madrid: Civitas.

Fiss, O. (1976). Groups and equal protection clause. Philosophy and Public Affairs, 5 (2), 107-177.

Gamonal, S. (2014). Fundamentos de Derecho Laboral. Santiago de Chile: Lexis Nexis.

- (2016). El daño moral en el artículo 489 del Código del Trabajo. Revista de Derecho de la Pontificia Universidad Católica de Valparaíso, 67 (2), 305-327. Disponible en: https://doi.org/10.4067/S0718-68512016000200010.

García de Enterría, E. (1959). La interdicción de la arbitrariedad en la potestad reglamentaria. Revista de Administración Pública, 30, 131-166.

Gauché, X. (2014). Análisis crítico de la Ley 20.609, que establece medidas contra la discriminación, a la luz del derecho internacional de los derechos humanos y las convenciones de la OEA sobre discriminación de 2013. Revista Chilena de Derecho y Ciencia Politica, 5 (1), 11-58. Disponible en: https://doi.org/10.7770/ rchdycp-V5N1-art708.

Giménez, D. (1999). Una manifestación polémica del principio de igualdad: Acciones positivas moderadas y de discriminación inversa. Valencia: Tirant lo Blanch.

Huepe, F. (2018). Discrecionalidad administrativa y razonabilidad. Santiago de Chile: Thomson Reuters.

Mackinnon, C. (1995). Hacia una teoría feminista de Estado. E. Martín (trad.). Madrid: Cátedra.

Martín, M. A. (2003a). Evolución del principio de igualdad en Estados Unidos. Nacimiento y desarrollo de las medidas de acción afirmativa en Derecho estadounidense. Revista Española de Derecho Constitucional, 23 (68), 151-194.

- (2003b). Fundamento y limites constitucionales de las medidas de acción positiva. Madrid: Civitas.

- (2004). Evolución histórica del principio de igualdad y paradojas de exclusión. Granada: Universidad de Granada.

Muñoz, F. (2013). No a «separados pero iguales» en Chile: un análisis del Derecho Antidiscriminación chileno a partir de su primera sentencia. Revista Estudios 
Constitucionales, 11 (2), 201-228. Disponible en: https://doi.org/10.4067/ S0718-52002013000200006.

Paredes, F. (2014). La garantía jurisdiccional de los derechos fundamentales. Santiago de Chile: Legal Publishing.

Rabossi, E. (1990). Derechos Humanos: El principio de igualdad y la discriminación. Revista del Centro de Estudios Constitucionales, 7, 175-192.

Rey, F. (2008). La discriminación múltiple, una realidad antigua, un concepto nuevo. Revista Española de Derecho Constitucional, 28 (84), 251-283.

- (2010). Igualdad entre mujeres y hombres en la Jurisprudencia del Tribunal Constitucional Español. Revista Estudios Constitucionales, 8 (2), 527-564. Disponible en: https://doi.org/10.4067/S0718-52002010000200015.

- (2011). ¿De qué hablamos cuando hablamos de igualdad constitucional? Anales de la Cátedra Francisco Suárez. Igualdad y Derecho Antidiscriminatorio, 45, $167-$ 181.

- (2017). Igualdad y prohibición de discriminación: De 1978 a 2018. Revista de Derecho Politico, 100, 125-171. Disponible en: https://doi.org/10.5944/ rdp.100.2017.20685.

Rosales, C. (2014). La acción de no discriminación arbitraria. En M. P. Silva (coord.). Acciones protectoras de derechos fundamentales (pp. 255-295). Santiago de Chile: Legal Publishing.

Rotunda, R. y Nowak, J. (1992). Treatise on Constitutional Law. Substance and Procedure (vol. 3; 2.a ed.). Saint Paul-, Minnesota: West Publishing CO.

Saba, R. (2016). Más allá de la igualdad formal ante la ley, ¿qué les debe el Estado a los grupos desaventajados? Buenos Aires: Siglo XXI Editores.

Serra, R. (2013). La mujer como especial objeto de múltiples discriminaciones. La mujer multidiscriminada. En R. Serra (coord.). La discriminación múltiple en los ordenamientos jurídicos español y europeo (pp. 15-44). Valencia: Tirant lo Blanch.

Sierra, E. (2018). El concepto de discriminación indirecta: su delimitación y aplicación en el derecho social comunitario europeo y español. En E. M. Blázquez (dir.). Los ODS como punto de partida para el fomento de la calidad del empleo femenino (pp. 11-26). Madrid: Editorial Dykinson. Disponible en: https://doi. org/10.2307/j.ctv9hvtgw.3.

Suay, J. (1985). El principio de igualdad en la justicia constitucional. Madrid: Instituto de Estudios de Administración Local.

Ugarte, J. L. (2013). El derecho a la no discriminación en el trabajo. Santiago de Chile: Legal Publishing.

Young, I. M. (2000). La justicia y la politica de la diferencia. S. Álvarez (trad.). Madrid: Ediciones Cátedra.

Zúñiga, F. (2002). Principio de no discriminación, principio de discriminación compensatoria e igualdad constitucional (discriminación por género y por edad). Anuario de Filosofía Jurídica y Social, 10, 237-260. 